\title{
Effect of Educational Program on Nurses' knowledge and Practice Caring for Patients on Mechanical Ventilation
}

\author{
Asmaa Bakry Mohamed ${ }^{1}$, Mervat Anwar Abdel-Aziz ${ }^{2}$, Mogedda Mohamed Mehany ${ }^{3}$ \& Khaled Mohamed \\ Morsy ${ }^{4}$. \\ 1. Clinical nurse specialist, in trauma intensive care unit Assuit University Hospital, faculty of Nursing, Assiut \\ University, Assiut, Egypt \\ 2. Assistant Professor of Critical \& Emergency Care Nursing, Faculty of Nursing, Assiut University, Assiut, Egypt. \\ 3. Assistant Professor of Critical \& Emergency Care Nursing, Faculty of Nursing, Assiut University, Assiut, Egypt. \\ 4. Assistant Professor of Critical \& Emergency Care unit, Faculty of medicine, Assiut University, Assiut, Egypt.
}

\begin{abstract}
Background: Mechanical ventilation is one of the most significant life-saving advancements in medical science; Nurses caring for patients on ventilator must be competent to provide effective nursing care for such group of patients, Effective educational program for nurse's staff will increase the quality of nursing care. Aim: To investigate the effect of educational program on nurses' knowledge and practice caring for patients on mechanical ventilation. Study design: Quasi-experimental research design was utilized in this study. Setting: The study was conducted in trauma ICU at Assiut University hospital. Sample: A convenience sample of all available nurses. The sample size was (50) nurse. Tools: Two tools were used for data collection, Tool one: nurses' knowledge assessment tool, Tool two Nurses practice assessment tool. Results: Nurses' knowledge scores improved after implementation of the educational program from ( $44 \%$ to $84 \%$ ), Also the observed nurses' practice scores improved from (38\%) before the educational program to (90\%) after the educational program. Conclusion: Nurses` knowledge and practice regarding the care of patients on ventilator in the trauma intensive care unit becomes to the satisfactory level after the educational program. Recommendation: Nurses need for in-service training programs to update their knowledge and practice regarding the care of patients on ventilator.
\end{abstract}

\section{Keywords: Mechanical Ventilation, Educational Program, Nurses`Knowledge \& Practice.}

\section{Introduction}

Mechanical ventilation is one of the most common medical therapies provided in the hospital setting. Patients with acute respiratory failure requiring mechanical ventilation are typically cared for in an intensive care unit (ICU). However, it has been renowned that increasing numbers of ventilatordependent patients are being treated outside of traditional ICUs. This practice of transferring such patients to non-ICUs has arisen primarily as a means to reduce the escalating medical costs for such a group of patients (Urner et al., 2018).

A ventilator is used to replace or assist spontaneous breathing. Invasive mechanical ventilator involves the use of an endotracheal tube, either through the mouth or through the nose, to push air into the trachea. While mechanical ventilator is normally, an intervention that only used to save a patient's life, but it does come with potential complications, such as alveolar damage, airway injury, pneumothorax, oxygen toxicity, and decreased cardiac input (Windisch et al., 2018).

There are wide-ranging reasons for patients requiring mechanical ventilation in the emergency department, with no absolute contraindications. Many time- honored indications for invasive ventilation are now identified, as appropriate indications for noninvasive ventilation and are addressed later, indications for mechanical ventilation range from loss of airway anatomy (edema, direct or indirect trauma, burns, and infection), loss of protective airway) mechanisms (intoxicants, brain injury, stroke, and inability to ventilate) (Clemons et al., 2016).

In order to provide the best comprehensive patient care while reducing healthcare costs, the nurse must have the knowledge, skills, and abilities to properly manage a patient receiving mechanical ventilation. It is essential that educators, students, and nurse practitioners strive to develop the knowledge necessary to successfully manage patients receiving ventilation support, Proper mechanical ventilator education strategies at all levels to the healthcare team will have a profound effect on increasing the quality of patient care in such field (Reynolds et al., 2017).

\section{Significance of the study}

Critical care nurses must have specialized skills and knowledge to be able to critically think rapidly in life and death situations. High-level cognitive and emotional competencies are associated with the 
technical and relational dilemmas encountered daily in such settings. One of the specific skills that are foundational for critical care nurses is to be able to have competent care for patients on the mechanical ventilator.

\section{Aim of the study}

To investigate the effect of educational program on nurses' knowledge and practice caring for patients on mechanical ventilation.

\section{Research hypothesis}

To fulfill the aim of the study, the following research hypotheses were formulated:

- There will be significant difference between posttest knowledge scores to the pretest knowledge scores following the implementation of the educational program.

- There will be significant difference between posttest skill scores to the pretest skill scores following the implementation of the educational program.

- A positive relationship will exist between knowledge and skills scores obtained by the critical care nurses after receiving the educational program.

\section{Subjects \& Methods \\ Research design;}

We used a quasi-experimental research design with one group pre-test and post-test approach to evaluate the effectiveness of a structured educational program for the present study. Thus, only one group observed twice (before and after introducing the independent variable).

\section{Study variable}

- The independent variable was the educational program.

- The dependent variable was a critical care nurse's level of knowledge and practice.

\section{Setting}

This study was conducted at the trauma ICU in Assuit university hospital.

\section{Subjects and population}

A convenience sample of all bedside nurses in trauma ICU who provide direct patient care and willing to participate in the study represented subjects of the current study. They had different nursing educational levels; bachelor, diploma and technical nursing.

\section{Study Tools}

Two tools were used in this study:

Tool (I); nurses' knowledge questionnaire: - this tool consisted of structured true or false, multiplechoice and list pre/posttest questionnaire tool. This tool was developed by the researcher after reviewing literature, to assess the knowledge level of the critical care nurses regarding the care of patients on mechanical ventilator. It was structured in the Arabic language.

This tool included two parts

Part (1): In addition to some selected demographic data for nurses as nurse ID, age, sex, marital status, qualification, years of experience and previous training program.

Part (2): nurses' knowledge as regarding the care of patients on mechanical ventilator as definition, indications, modes, alarms, setting, complications....etc.

\section{Scoring system:}

Each right answer was given one score, the number of questions was 38 .

The total score of the questionnaires was less than $(60 \%)$ were considered unsatisfactory level. While those who obtained $(60 \%)$ or above were considered satisfactory according to the range of the total scores, it laid between (0-38 degrees).

Tool (II); Nurses practice observation checklist The observation checklist was developed to assess the practical aspects of the basic nurses' procedure about care of patient on mechanical ventilator as the following

- Oropharyngeal airway.

- Nursing care pre, during and post endotracheal tube insertion.

- Daily care for the intubated patient.

- Caring for a patient on a mechanical ventilator.

- Suctioning.

- Nursing care during the weaning process.

- Nursing care during nasogastric tube insertion.

- Care of patients during arterial blood gas puncture.

- Central venous pressure monitoring.

Scoring system: Each step was observed, categorized and scored as follow: two degrees for each step that was done correct, one degree for each step done but incorrect method and zero for step that was not done. The total score for all the steps was less than $(60 \%)$ were considered inadequate practical level. $(60 \%)$ or above were considered adequate practical level.

\section{Methods}

The study was conducted on three phases (preparatory phase, implementation phase and evaluation phase)

\section{Preparatory phase}

This phase involved:

- Preparation of the data collection tools which was developed by the researcher was based on reviewing the relevant literature:- (Reynolds, et al., 2017), (Jun, et al., 2016) \& (Urner, et al., 2018) 
- Tools content validity; jury of 5 experts in the field of critical care nursing and critical care medicine from Assuit university hospital, Testing content validity of the study tools and the necessary modifications were done.

- A pilot study was done for $10 \%$ of the nurses from the sample to check the clarity and understanding of the study tools and the necessary modifications done prior data collection. This pilot sample was to estimate the time needed to answer the study tools. Pilot study excluded from the studied sample and it replaced by another group of nurses.

- Tools the reliability: knowledge assessment tool and practice assessment tools were tested using Cronbach coefficient alpha.

\section{- Ethical consideration}

- The research proposal was approved from the ethical committee in the faculty of nursing.

- There was no risk in study subject during application of the research.

- The study was following common ethical principles in clinical research.

- Written consent was obtained from nurses that are willing to participate in the study, after explaining the nature and purpose of the study.

- Data was assured for confidentiality and anonymity.

- Study subject had the right to refuse to participate and / or withdraw from the study without any rational and at any time.

- Study subject privacy was considered during data collection.

Development of the educational program

The researcher developed the educational program, after reviewing the literature and based on nurses identified need post the pretest. The following steps were adopted to develop the program.

- Stating the program general and specific objectives.

- Planning the program: the content of the program was arranged into five sessions in addition to preliminary one.

The content of the program covered two parts related to Data collection tools

- Knowledge about the mechanical ventilator.

- The practice of the procedures regarding care of patients on ventilator

Theoretical part included:

- Anatomy and physiology of the respiratory system.

- Mechanical ventilation definition, modes, indications, complications and alarms.
- Weaning definition, methods, criteria and causes of weaning failure

Practical part included

- Apply care of patients on ventilator

- Implement suctioning procedure

- Implement C.V.P measurement.

- Assess the implementation of the oral airway insertion procedure.

- Assess the implementation of nasogastric tube insertion.

- Nursing care of patients pre, during and post endotracheal tube insertion

- Care of patients during arterial blood gases puncture.

\section{Learning environment}

The program was conducted in the head nurse's office in the trauma intensive care unit at Assuit university hospital.

Implementation phase

- Once permission was granted to precede with the proposed study the researcher-initiated data collection.

- Data was collected from trauma ICU at Assuit university hospital.

- At the beginning of the interview, the researcher introduced herself to initiates line of communication.

- The Interview questionnaire filled after the purpose of the study explained to the nurse before answering the question-using tool (I) "1st and 2nd parts".

- An observational checklist was carried out during nurses giving care for patients on mechanical ventilator and without prior knowledge, the researcher observed nurses performance in the morning and afternoon shift tool (II).

- Each nurse was involved in the study assessed for knowledge, using tool (I) twice pre and post program implementation.

- Each nurse observed while performing procedure during the routine care of managing patient on mechanical ventilator in the intensive care unit, using tool (II) twice pre and post program implementation.

- The program implemented for subgroups each contained ten nurses on five sessions in addition to the preliminary one.

Preliminary session

In this session, the researcher met the participants and explained the objectives, contents, and methods of evaluation of the program.

Session I include:

Definition of mechanical ventilation (MV), indications, modes and complications, for 30 minutes. 


\section{Session II include}

Nursing care of patient on MV as; suction, ABGs and ideal use of imbue bag, for 30 minutes.

\section{Session III include:}

Weaning from MV that includes preparations, methods and indications, for 45 minutes.

\section{Session IV include}

Different methods of Airway insertion, nasogastric tube insertion, endotracheal tube insertion preparation, for 30 minutes.

\section{Session V include}

Chest physiotherapy, range of motion, C.V.P measurement and benefits of change patient's position, for 45 minutes

* Group discussion was encouraged with continuous feedback to ensure understanding and achievement of specific objectives of the program.

* Picture and video clips about the procedures were used in sessions for demonstration.

* In the last session, the researcher summarized and emphasized the important points.

\section{Evaluation phase}

Every nurse included in the present study was evaluated twice, using tool (I) and tool (II) before the implementation of the educational program, immediately after application of the program to test the effectiveness of the program on nurse's knowledge and practice.

\section{Statistical analysis}

Collected data were analyzed and tabulated. The researcher used an appropriate statistical method and tests for analysis of the result. The statistical Package for (SPSS) version (23) was used to analyze data. Descriptive statistics were used for the quantitative data in questionnaire and the demographic data. Descriptive statistics included frequencies, and percentages, Pearson Correlation (Correlation is significant at the 0.05 level). The level of significance for this study was set at $(\mathrm{p} \leq 0.05)$ to detect any indication of differences found in the data available.

\section{Results}

Table (1): Percentage distribution of demographic data among the studied nurses $(n=50)$.

\begin{tabular}{|c|c|c|}
\hline Variable & N. (50) & $\%$ \\
\hline \multicolumn{3}{|l|}{ Age: (years) } \\
\hline$<25$ & 25 & 50.0 \\
\hline$\geq 25$ & 25 & 50.0 \\
\hline Mean \pm SD & \multicolumn{2}{|c|}{$25.26 \pm 3.83(19.0-35.0)$} \\
\hline \multicolumn{3}{|l|}{ Marital status } \\
\hline Single & 34 & 68.0 \\
\hline Married & 16 & 32.0 \\
\hline \multicolumn{3}{|l|}{ Academic qualifications } \\
\hline Nursing secondary school & 6 & 12.0 \\
\hline Nursing technical institute & 26 & 52.0 \\
\hline Nursing bachelor Degree & 18 & 36.0 \\
\hline \multicolumn{3}{|l|}{ Years of experience } \\
\hline$<1$ year & 18 & 36.0 \\
\hline $1-<5$ years & 16 & 32.0 \\
\hline $5-<10$ years & 7 & 14.0 \\
\hline$\geq 10$ years & 9 & 18.0 \\
\hline \multicolumn{3}{|l|}{ Attending training courses } \\
\hline Yes & 18 & 36.0 \\
\hline No & 32 & 64.0 \\
\hline \multicolumn{3}{|l|}{ No. of training courses } \\
\hline One & 15 & 83.3 \\
\hline Two & 3 & 16.7 \\
\hline
\end{tabular}


Table (2): percentage distribution of nurse's Knowledge regarding to mechanical ventilation (MV) before and after the educational program.

\begin{tabular}{|c|c|c|c|c|c|}
\hline \multirow[t]{2}{*}{ Assessment nurse's knowledge about MV } & \multicolumn{2}{|c|}{$\begin{array}{l}\text { Pre-test } \\
(n=50)\end{array}$} & \multicolumn{2}{|c|}{$\begin{array}{c}\text { Post-test } \\
(n=50)\end{array}$} & \multirow[t]{2}{*}{ P-value } \\
\hline & N. & $\%$ & $\mathbf{N}$. & $\%$ & \\
\hline \multicolumn{5}{|l|}{ Definition of Mechanical ventilation } & \multirow{3}{*}{$0.000 *$} \\
\hline Correct & 38 & 76.0 & 50 & 100.0 & \\
\hline Incorrect & 12 & 24.0 & 0 & 0.0 & \\
\hline \multicolumn{5}{|l|}{ Indication of Mechanical ventilation } & \multirow{3}{*}{$0.001 *$} \\
\hline Correct & 35 & 70.0 & 48 & 96.0 & \\
\hline Incorrect & 15 & 30.0 & 2 & 4.0 & \\
\hline \multicolumn{5}{|l|}{ Complications Mechanical ventilation } & \multirow{3}{*}{$0.026^{*}$} \\
\hline Correct & 31 & 62.0 & 41 & 82.0 & \\
\hline Incorrect & 19 & 38.0 & 9 & 18.0 & \\
\hline \multicolumn{5}{|l|}{ Ventilator setting: Exhaled tidal volume } & \multirow{3}{*}{$0.001 *$} \\
\hline Correct & 29 & 58.0 & 44 & 88.0 & \\
\hline Incorrect & 21 & 42.0 & 6 & 12.0 & \\
\hline \multicolumn{5}{|l|}{$\begin{array}{l}\text { Modes of Mechanical ventilation: SIMV mode of } \\
\text { ventilation: }\end{array}$} & \multirow{3}{*}{$0.028 *$} \\
\hline Correct & 21 & 42.0 & 32 & 64.0 & \\
\hline Incorrect & 29 & 58.0 & 18 & 36.0 & \\
\hline \multicolumn{5}{|l|}{ Alarms of Mechanical ventilation: Low pressure alarm } & \multirow{3}{*}{$0.000 *$} \\
\hline Correct & 16 & 32.0 & 40 & 80.0 & \\
\hline Incorrect & 34 & 68.0 & 10 & 20.0 & \\
\hline \multicolumn{5}{|l|}{ Complications associated with PEEP } & \multirow{3}{*}{$0.000 *$} \\
\hline Correct & 36 & 72.0 & 49 & 98.0 & \\
\hline Incorrect & 14 & 28.0 & 1 & 2.0 & \\
\hline \multicolumn{5}{|l|}{$\begin{array}{l}\text { Causes of high pressure's alarm in Mechanical } \\
\text { ventilation: }\end{array}$} & \multirow{3}{*}{$0.000 *$} \\
\hline Correct & 20 & 40.0 & 42 & 84.0 & \\
\hline Incorrect & 30 & 60.0 & 8 & 16.0 & \\
\hline
\end{tabular}

*statistical significant difference $(p<0.05)$

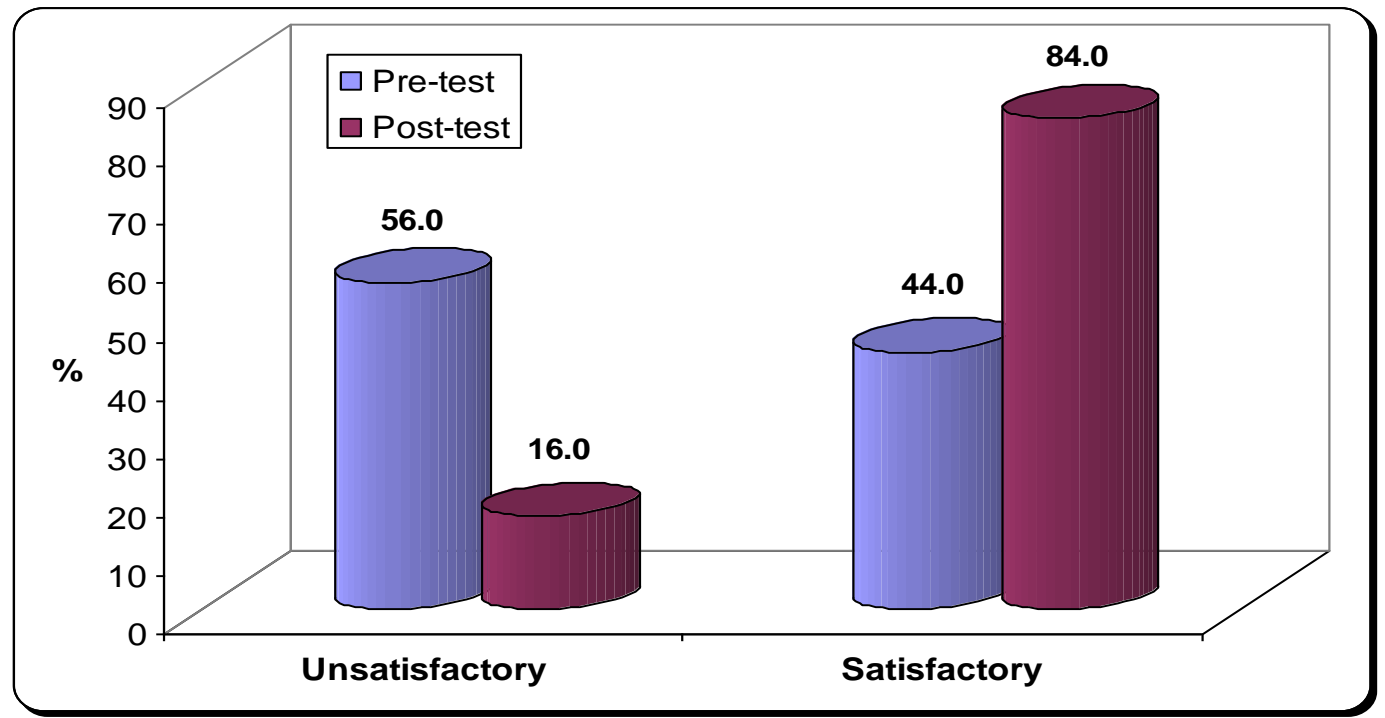

Figure (1): the total score of nurses' Knowledge level in pre-test and post-test. 
Table (3): the total score for nurses' Practices level in pre-test and post-test.

\begin{tabular}{|c|c|c|c|}
\hline \multirow[t]{2}{*}{ the total score for nurses' level of Practices } & $\begin{array}{c}\text { Pre-test } \\
(n=50)\end{array}$ & $\begin{array}{c}\text { Post-test } \\
(n=50)\end{array}$ & \multirow[t]{2}{*}{ P-value } \\
\hline & Mean \pm SD & Mean \pm SD & \\
\hline Oropharyngeal airway & $10.66 \pm 3.78$ & $14.56 \pm 2.18$ & $0.000 *$ \\
\hline $\begin{array}{l}\text { Nursing care pre, during and post Endotracheal tube } \\
\text { insertion }\end{array}$ & $19.62 \pm 5.92$ & $28.58 \pm 5.47$ & $0.000^{*}$ \\
\hline Daily care for intubated patient & $5.86 \pm 2.67$ & $9.84 \pm 2.14$ & $0.000 *$ \\
\hline Caring for a patient on a mechanical ventilator & $19.46 \pm 6.62$ & $25.78 \pm 4.66$ & $0.000 *$ \\
\hline Suctioning & $23.58 \pm 4.10$ & $32.52 \pm 4.36$ & $0.000 *$ \\
\hline Nursing care for weaning & $6.30 \pm 2.32$ & $9.22 \pm 1.73$ & $0.000^{*}$ \\
\hline Nasogastric tube insertion & $19.50 \pm 4.26$ & $27.78 \pm 4.35$ & $0.000 *$ \\
\hline Care of patients during Arterial blood gas puncture & $25.16 \pm 5.02$ & $35.34 \pm 4.79$ & $0.000 *$ \\
\hline Central venous pressure monitoring & $16.82 \pm 4.24$ & $18.98 \pm 2.71$ & $0.003 *$ \\
\hline Total Practices score & $146.96 \pm 32.83$ & $202.60 \pm 27.53$ & $0.000 *$ \\
\hline
\end{tabular}

*statistical significant difference $(p<0.05)$

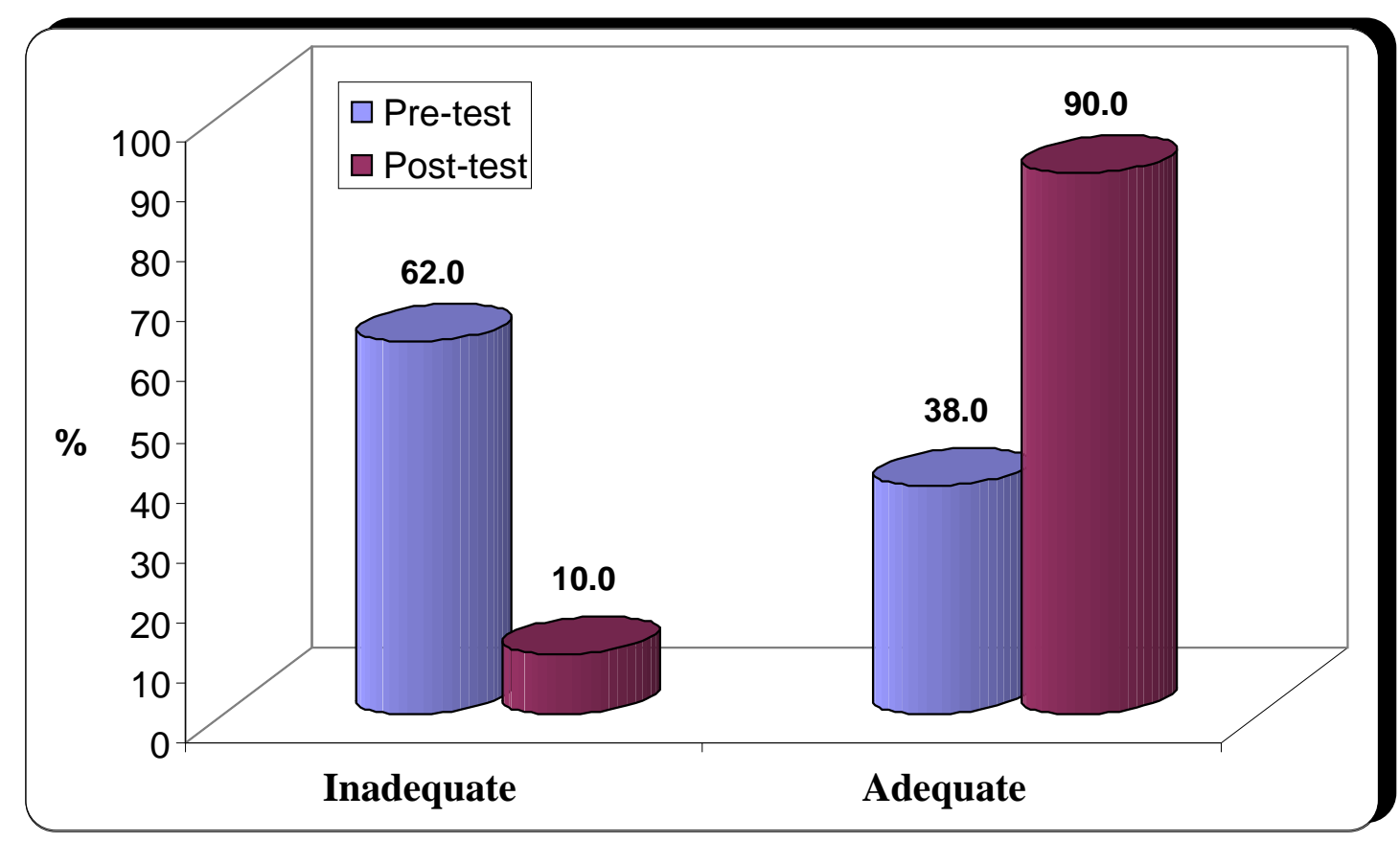

Figure (2) the total score for nurses' Practices level in pre-test and post-test 


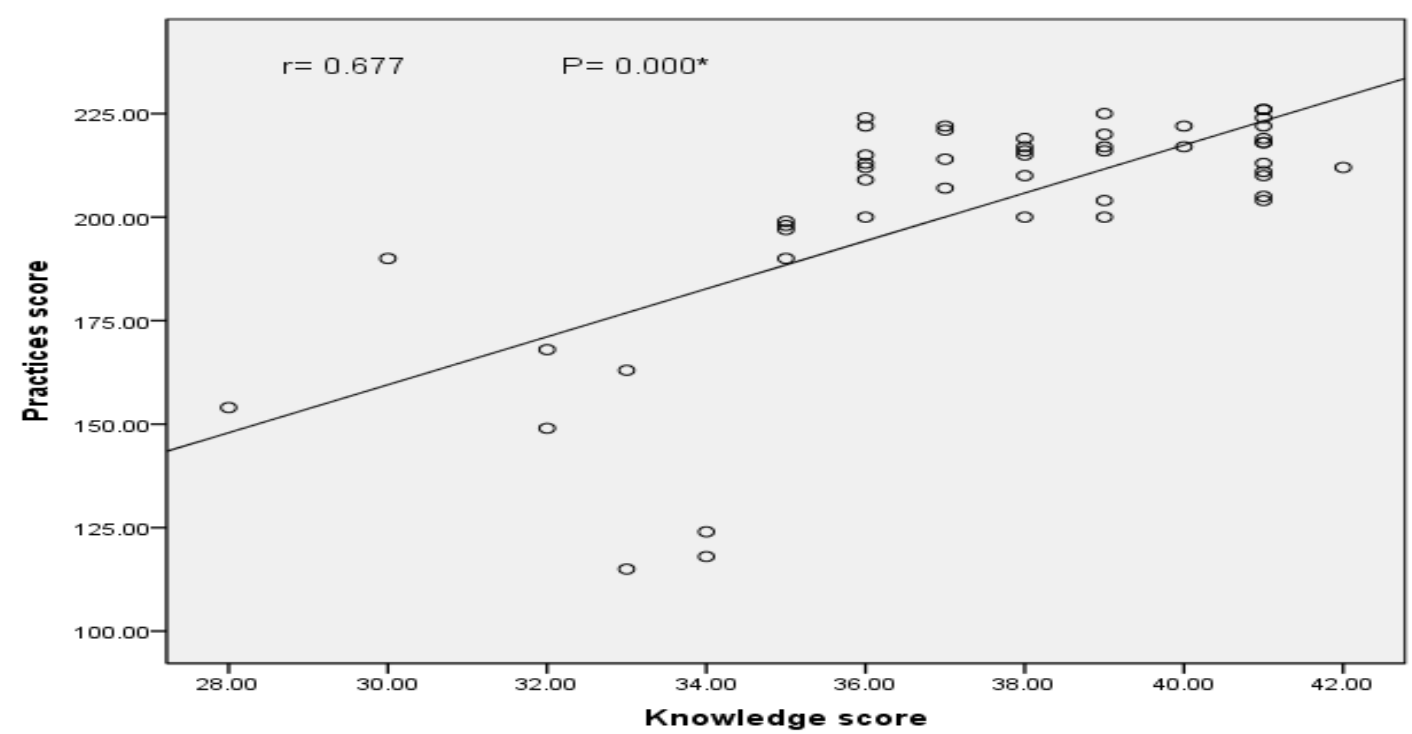

Figure (3): correlation between the total score of nurses' knowledge and practice after the educational program.

Table (1): Show demographic data of studied nurses, it showed that $50 \%$ of them were in the age group less than 25 years old, $68 \%$ were single, all sample were female nurses, concerning their educational level $52 \%$ of the nurses with technical institute and $36 \%$ of nurses hold nursing bachelor degree. Moreover, the majority of the nurses $36 \%$ had experienced less than 1 year. Concerning their previous training courses, $64 \%$ of them had not received any training courses, while $83.3 \%$ of them had two courses.

Table (2): The answers of (76\%, 70\% and 62\% respectively) of nurses regarding MV (definition, indications and complications) respectively were correct before the educational program, While $(100 \%, 96 \%$ and $82 \%)$ respectively answers of them were correct after the educational program with significant differences $(\mathrm{p}<0.05)$.

The table also reveals that, the answers of $(58 \%$, $42 \%, 32 \%, 72 \%$ respectively)of nurses regarding (ventilator setting, modes and alarms of MV ,and complication of PEEP respectively) correct before the program and $(86 \%, 88 \%, 64 \%, 80 \%, 98 \%$ respectively) answers of them were correct after the program with significant differences $(\mathrm{p}<0.05)$.

This table also reveals that the answers of $(20 \%)$ of nurses regarding (causes of high alarm) were correct before the program and $(62 \%)$ answers of them were correct after the program with significant differences $(\mathrm{p}<0.05)$.

Table (3): Illustrates that the total score for nurses' practices level in pre-test and post-test showed statistically significant differences between nurses' practices categories indicating adequate practice level after the educational program compared with practice before the educational program.

Figure (1): The total score of nurses' knowledge level in pre-test and post-test:-

It showed that the answers of the majority of studied nurses $84 \%$ were satisfactory after the educational program compared to $44 \%$ satisfactory level only before the educational program, with statically significant differences $(\mathrm{p}<0.05)$.

Figure (2): The total score for nurses' practices level in pre-test and post-test

This figure shows that the majority of studied nurses (90\%) were adequate practices the skills during patients care after the educational program, compared to only $38 \%$ adequate practices level score before the educational program implementation with statically significant differences $(\mathrm{p}<0.05)$.

Figure (3): Shows the correlation between total score of nurses' knowledge and practice after the educational program; there was a significant positive correlation between the score of knowledge and the score of practice with statically significant differences $(p<0.05) . r=0.677, p=0.000 *$

\section{Discussion}

Critical care nurses must have the knowledge, skills, and abilities to properly manage a patient receiving mechanical ventilation. It is essential that educators, students, and nurse practitioners strive to develop the knowledge necessary to successfully manage patients receiving ventilator support. (Jun et al., 2016). 
This discussion will cover the main result findings as follow:

Demographic characteristics of studied nurses:

The study result revealed that all of the nurses were females; half of them were in the age group less than 25 years old. The majority of them were single. This finding was not in the same line with; Ponikowski et al., (2016) who mentioned that; the administrators selected older age nurses, to be able to perform mainly tasks in the intensive care unit effectively.

Concerning nurses' educational level more than half of them, hold technical institute. Moreover, one third of the studied nurses had experienced less than 1 year and another one-third had experienced more than 1 year to 5 years. The few years of experience could be explained by rotating of nurses from a unit to another within hospital.

While, Shorofi \& Arbon, (2017) revealed that the majority of nurses working in ICU their ages ranged from 20-40 years old, married, female, and have diploma of nursing, more than half of them had experienced more than 5 years.

This result was not incongruent with Eastwood et al., (2012) who reported that the majority of nurses who are working in ICU generally had a bachelor degree in nursing.

According to the National Institute for Clinical Excellence, (2012), stated that nurses with few years of experience may require maximum additional instructions before they are ready to take a patient assignment, nurses working in one clinical specialty may need the amount of instructions to be acquired through the training program.

In relation to attending any previous training program, the participant nurses were not attaining of any previous training. This due to the hospital did not have a staff development program. This result was supported by Rochester (2017) who said that nurses who are working in the intensive care unit need additional education to provide optimal care for patients on mechanical ventilator. In addition to Chen et al., (2018) who mentioned that in their study participants from nurses had never attended training courses on mechanical ventilator.

The previous result contradicted with Norush et al., (2014); who stated that health care provision the requirement of in-service training programmers for nurses. Also stated that continuous professional development by education and training after getting the of qualification or the registration help nurses in improving patient care and enable professional nurse practitioners to provide quality nursing care and service to their patients.
Knowledge assessment of the studied nurses Regarding nurses' knowledge about mechanical ventilation for such group of patient, the study results revealed that there was a statistical difference with $\mathrm{p}$. value $(<0.05)$ between the level of nurses' knowledge pre and after the implementation of the education program.

Nurses must be knowledgeable about the function and limitations of ventilator modes. It is essential that nurses thoroughly understand the basics of ventilator support, including ventilator modes, settings, and alarms. Only a brief review of the commonly used ventilation modes and basic operation provided in the program booklet, interested readers referred elsewhere for more in-depth information. (Akıncı et al., 2010).

Kanki, (2019) reported that each organization and profession must set standards and objectives to guide individuals and practitioners in performing safe and effective care. In addition, leaders and managers must be aware that subordinates know and understand the standards, employees also must be aware that their performance will be measured in terms of their ability to meet the established standards.

At the same time, it is felt that the low level of intensive care nurses qualifications and participation in the in-service training courses related to intensive care nursing affected on these results. Alongside this, it was found that nurses' education levels and duration of professional experience decreased regarding the care of patients on MV.

This result is in accordance with the results of another study carried by Shamian et al., (2016). However, in contrast to the findings of other similar studies, it found in our study that when nurses' duration of work in the intensive care unit increased, their level of knowledge did not increase correspondingly. This difference is thought to stem from the fact that in this country, as nurses' years of experience increase, they have different roles in the intensive care unit and their working hours with patients decrease. As well also, the number of patients to whom they provide care and treatment in their working hours' decreases, and they tend to participate less frequently in the in-service training programs.

Skills assessment of the studied nurses

The present study showed that the total score for nurses' practices level in pre-test and post-test showed statistically significant differences between nurses' practices categories indicating adequate practice after the educational program compared with practice before the educational program. This was in the same line with Fathimath et al., (2013) who mentioned that; regarding practices result of pretest 
indicates that the level of practices significantly increase with the level of education but effects of an educational program make the correlation not significant in the posttest.

Moreover, the nurses lack the efficiency of updating their practice after being in the clinical environment for a longer time and possible explanation for this finding could be the workload. (Vargas et al., 2015)

Slater et al., (2018) reported that teaching programs for nursing staff play an important role in assisting staff nurses to develop and enhance their skills needed to provide high standards of care to their patients. This agreed with the present study as nurse's knowledge and practice improved after implementation of the educational program.

Koo et al., (2016) in the same line with the current study findings, as their study revealed that improvement in nurses' practice after the attendance of continuing nursing education sessions. Research findings indicated that nursing education programs improve knowledge, practice and attitudes.

Regarding the relationship between the total nurses' knowledge and their practice scores:

The current study found that there was a statistical significant difference in nurses' performance (knowledge and practice) after giving the educational program. This study was in the line with Ozekcin et al., (2015) who expressed that the nursing educational programs could be effective in improving the knowledge and practice among staff nurses.

Findings of the present study found that there is a positive correlation between nurses' knowledge and practice. This agreed with Ndwiga et al., (2017) who stated that a statistical significant correlation between participants' scores of knowledge and practice pre and post program implementation.

In addition, this finding is in agreement with Hassan, \& Wahsheh, (2017) who indicated that there were highly significance differences through the phases of study regarding knowledge and practice of the nursing management for the patient on mechanical ventilator. $(\mathrm{P}=0.0001)$ among the studied nurses included.

There was statistically significant positive correlation found between knowledge and practice according to Falk \& Wallin, (2016) as they revealed a statistically significant positive correlation between knowledge and practice of nurses caring for patients on mechanical ventilator.

The higher the nurses' knowledge, the more they used the safety measures in their practices. Literature reports that there was a gap between the nurses' knowledge and their actual behavior with respect to the use of the standard of care (Tsai et al., 2016).
Finally, the findings of the present study supported the research hypothesis that nurses working in the emergency unit and exposed to the educational program about mechanical ventilation will show high score of knowledge and practice in the result of the posttest more than the pretest.

\section{Conclusion}

The total scores of nurses' knowledge regarding care of patients on Mechanical ventilator, shows that $(56 \%)$ of studied nurses had unsatisfactory knowledge score, compared to $(84 \%)$ satisfactory knowledge score after the educational program and the total score of practice shows $(62 \%)$ inadequate practice score before the educational program, compared to $90 \%$ adequate practice score after the educational program. Also observed a positive correlation between the total score of nurses' knowledge and practice after the educational program with statically significant differences $(\mathrm{p}<0.05)$. Level of knowledge and practice, which could reflect the lack in their scientific preparation, the educational programs prepared for the nursing staff constitute an important part in improving nursing care offered for such a group of patients.

\section{Recommendations}

Based on the results of the present study, the following recommended:

Continuous nursing education and in-service training programs at critical care units should be organized within Assiut University Hospital and equipped with the necessary educational facilities and materials necessary to upgrade the knowledge and practice of nurses, which will improve nursing care offered and patients' outcome.

Nurses should add to their routine duties the regular reading to update their performance. They should always be encouraged to attend scientific meetings and conferences to keep pace with the rapid growing plenty of knowledge and practice necessary for proper effective nursing service.

\section{References}

1. Akıncı C., Akar N., Ayyıldız A., Atalan K., Ayyıldız A., (2010): Yo־ gun bakım hems, irelerinin ventilat" or ilis kili pn“omoni ile ilgili bilgilerinin de gerlendirilmesi. T"urk

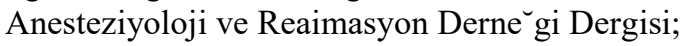
38: 45-51.

2. Chen, Y., Niu, M., Zhang, X., Qian, H., Xie, A., \& Wang, X., (2018): Effects of home-based lower limb resistance training on muscle strength and functional status in stable chronic 
obstructive pulmonary disease patients. Journal of clinical nursing, 27(5-6), e1022-e1037.

3. Eastwood, G., Reade, M., Peck, L., Baldwin, I., Considine, J., \& Bellomo, R., (2012): Critical care nurses' opinion and self-reported practice of oxygen therapy: a survey. Australian Critical Care, 25(1), 23-30.

4. Falk, A., \& Wallin, E., (2016): Quality of patient care in the critical care unit in relation to nurse patient ratio: A descriptive study. Intensive and Critical Care Nursing, 35, 74-79.

5. Fathimath S., Jancy G., Jancy T., (2013): Assessment of knowledge regarding mechanical ventilation among staff nurses working in selected hospital Mangalore with a view to develop an information pamphlet. International Journal of Recent Scientific Research.;4(9):1410-1413

6. Hassan, Z., \& Wahsheh, M., (2017): Knowledge level of nurses in Jordan on ventilator-associated pneumonia and preventive measures. Nursing in critical care, 22(3), 125132

7. Julia Clemons M., \& Mark Kearns M., (2016): Invasive Mechanical Ventilation, Hospital Medicine Clinics, 2016, Elsevier, Volume 5, Issue 1 Pages 17-29.

8. Jun, J., Kovner, C., \& Stimpfel, A., (2016): Barriers and facilitators of nurses' use of clinical practice guidelines: an integrative review. International Journal of Nursing Studies, 60, 54-68.

9. Kanki, B., (2019): Communication and crew resource management. In Crew resource management (pp. 103-137). Academic Press.

10. Koo, E., McNamara, S., Lansing, B. Olmsted, R., Rye, R., Fitzgerald, T., \& Team, T., (2016): Making infection prevention education interactive can enhance knowledge and improve outcomes: Results from the Targeted Infection Prevention (TIP) Study. American journal of infection control, 44(11), 1241-1246.

11. Mahmoud, A., Alseed, H., Abdallah, H. M. A., Awad, A., \& Elhussein, G., (2016): Assessment of knowledge and practice of nurses regarding oxygen therapy in el malk nimir university hospital.,European Journal of Pharmaceutical and Medical Research ,3(4), 3035

12. National institute for clinical excellence, (2012): Published in the internet from http://www.nice.org. UK/Clin-guide/clingudmain.html
13. Ndwiga, C., Warren, C., Ritter, J., Sripad, P., \& Abuya, T., (2017): Exploring provider perspectives on respectful maternity care in Kenya: "work with what you have". Reproductive health, 14(1), 99.

14. Norush, T., Van Rooyen, D., Strumpher, J., (2014): In-service education and training as experienced by registered nurses. PubMed: 27(4):63-72.

15. Ozekcin, L., Tuite, P., Willner, K., \& Hravnak, M., (2015): Simulation education: early identification of patient physiologic deterioration by acute care nurses. Clinical Nurse Specialist, 29(3), 166-173

16. Ponikowski, P., Voors, A., Anker, S., Bueno, H., Cleland, J., Coats, A., \& Jessup, M., (2016): 2016 ESC Guidelines for the diagnosis and treatment of acute and chronic heart failure: The Task Force for the diagnosis and treatment of acute and chronic heart failure of the European Society of Cardiology (ESC). Developed with the special contribution of the Heart Failure Association (HFA) of the ESC. European journal of heart failure, 18(8), 891-975.

17. Reynolds, A., Osborne, T., Waggoner, J., Melton, R., Motarjemi, R., Schulze, J., \& Chau, D., (2017): Advances in Health Education Technology. Using Technology to Improve Care of Older Adults, Springer Publishing Company, ch13, p287.

18. Rochester U., (2017): Bone Marrow Transplant/Hematology - EI 94, Mayo clinic, Eisenberg 94 , Bone Marrow Transplant/ Hematology , Dec 17, 2017, available on https:// www. linked in. com/jobs/view/registered-nurse

19. Shamian, J., Kerr, M., Laschinger, H., \& Thomson, D., (2016): A hospital-level analysis of the work environment and workforce health indicators for registered nurses in Ontario's acute-care hospitals. Canadian Journal of Nursing Research Archive, 33(4)

20. Shorofi, S., \& Arbon, P., (2017): Complementary and alternative medicine (CAM) among Australian hospital-based nurses: knowledge, attitude, personal and professional use, reasons for use, CAM referrals, and sociodemographic predictors of CAM users. Complementary therapies in clinical practice, 27, 37-45.

21. Slater, P., Edwards, R., \& Badat, A., (2018): Evaluation of a staff well-being program in a pediatric oncology, hematology, and palliative 
care services group. Journal of healthcare leadership, 10, 67.

22. Tsai, C., Lu, K., Wang, H., Yu, T., Sun, F., Chiang, C., \& Lin, H., (2016): Clinical and therapeutic implications of neuroendocrine prostate cancer: A long winding road to cure. Urological Science, 2(27), S56-S57.

23. Urner, M., Ferreyro, B., Douflé, G., \& Mehta, S., (2018): Supportive Care of Patients on Mechanical Ventilation. Respiratory care, volume 63 issue (12), pp. 1567-1574.

24. Vargas F., Saint-Leger M., Boyer A., (2015): Physiologic effects of high-flow nasal cannula oxygen in critical care subjects. Respiratory Care. 2015, 60(10):1369-76.

25. Windisch, W., Geiseler, J., Simon, K., Walterspacher, S., Dreher, M., \& Guideline Commission. (2018): German national guideline for treating chronic respiratory failure with invasive and non-invasive ventilation: revised edition 2017-part 1. Respiration, volume 96 issue (1), pp66-97. 